\title{
ASSOCIATION OF DYSLIPIDEMIA AND HYPER- HOMOCYSTEINEMIA IN EPILEPTIC PATIENTS ON CARBAMAZEPINE MONOTHERAPY.
}

1. MBBS, M.Phil Demonstrator Biochemistry Bolan Medical College, Quetta. 2. MBBS, M.Phil

Assistant Professor Biochemistry Fatima Jinnah Dental College, Karachi.

3. MBBS, M.Phil

Assistant Professor Pathology

(Hematology)

Bolan Medical College, Quetta.

Correspondence Address:

Dr. Shazia Bano

H. No. 564 , St. No. 12 ,

Railway Housing Society Near SBK University,

Brewery Road, Quetta.

drshazia2000@yahoo.com

Article received on:

26/12/2018

Accepted for publication: $15 / 06 / 2019$

\begin{abstract}
Shazia Bano', Syed Munawar Alam², Saima Iram ${ }^{3}$
ABSTRACT... Objectives: To observe the association between dyslipidemia and homocysteine level in epileptic patients; especially on carbamazepine monotherapy. Study Design: Cross sectional study. Setting: Neurology Department and Epilepsy Centre of Jinnah Post Graduate Medical Centre, Karachi. Period: From January 2015 - January 2016. Material \& Methods: Total 300 subjects, aged more than 15 years were included and divided into three groups. Group A (100 healthy individuals) was control group, Group B (100 newly diagnosed epileptic patients without antiepileptic therapy), Group C (100 epileptic patients on Carbamazepine therapy, which was further subdivided into $\mathrm{C}-\mathrm{I}(\mathrm{n}=33)$ had epileptic patients on Carbamazepine therapy less than 1 year, $C-I I(n=33)$ comprised of epileptic patients on Carbamazepine therapy 1-2 years and C-III $(n=33)$ had epileptic patients on Carbamazepine therapy more than 2 years. Serum lipid profile and homocysteine levels were measured. Results: In patients with different durations of carbamazepine monotherapy; a noteworthy incremental trend in the levels of homocysteine, total cholesterol, triglyceride, low density lipoprotein cholesterol, very low density lipoprotein cholesterol was observed. Homocysteine was found positively correlated with total cholesterol, triglyceride, low density lipoprotein cholesterol, very low density lipoprotein cholesterol. Conclusion: In our study dyslipidemia was associated with hyperhomocysteinemia, which in turn was correlated with atherosclerosis in CBZ treated epileptic patients.
\end{abstract}

Key words: $\quad$ AEDs, Atherosclerosis, CBZ Monotherapy, Dyslipidemia, Hyperhomocysteinemia.

Article Citation: Bano S, Alam SM, Iram S. Association of Dyslipidemia and Hyperhomocysteinemia in epileptic patients on carbamazepine monotherapy. Professional Med J 2020; 27(2):230-236.

DOI: 10.29309/TPMJ/2020.27.2.2995

\section{INTRODUCTION}

Neurological diseases have their due share in the global disease burden; contributing well over $10 \%$ as reported in 2000 and was estimated to increment by $15 \%$ on a yearly basis for the next two decades. Moreover epilepsy is found to be pitching in at a rate of approximately $1 \%$ in the aforementioned pie. ${ }^{1}$

Global prevalence of epilepsy is between 5 - 10 cases per 1000 persons and it matches the upper quartile in Pakistan being 9.9 per 1000 persons. ${ }^{2}$ The mortality rate in epileptic patients is increased 2 - 3 folds as compared to the general population moreover sudden death is 20 times more often than general population. ${ }^{3}$

The prevalence and incidence of cardiovascular diseases (CVDs) are incrementing rapidly and are the leading cause of death in the developing sphere. It is anticipated that CVDs will go beyond the infectious diseases, by the year 2020, as the world's principal cause of death. ${ }^{4}$ Hyperhomocysteinemia (HHcy) is a vital predictor of cardiovascular diseases. ${ }^{5}$ Normal homocystein level is $5-15 \mu \mathrm{mol} / /$ and anything above that would be labelled as Hyperhomocysteinemia (H Hcy). ${ }^{6}$

Dyslipidemia is a deviation in plasma lipoprotein functions and/or in their concentration and is an significant risk factor for atherosclerosis. ${ }^{7}$ Previous studies have shown that total cholesterol (TC) and low density lipoprotein-cholesterol (LDL-C) are important and independent predictors of cardiovascular morbidity and mortality. ${ }^{8}$ 
Antiepileptic drugs (AEDs) like Carbamazepine (CBZ) bring changes in TC, LDL-C, high density lipoprotein- cholesterol (HDL-C) and triglycerides (TG). ${ }^{9}$ Dyslipidemia is the earliest sign which can be detected during childhood and one of the major risk factor for atherosclerosis. ${ }^{10}$ Researchers have established atherosclerotic lesions in the aorta of mice who were on high-cholesterol and highlinoleic diet. ${ }^{11}$

Overwhelming evidence of the published data have implied that the long term use of antiepileptic drugs correlates with the increased level of plasma Hcy; which may by causing vascular endothelial injury, increases the risk of atherosclerosis. ${ }^{12}$ It eventually increases the risk of cardiovascular incidents and associated high mortality. ${ }^{9}$ Recent studies have also indicated that CBZ like AEDs are potent activators of the cytochrome P450 system (CYPs). ${ }^{13}$ Cytochrome P450 system strongly effects the lipid profile and Hcy. Therefore it would be safe to transcribe that the antiepileptic drugs like CBZ may increase the risk of atherosclerosis by effecting the lipid metabolic pathways and hepatic enzyme system. ${ }^{9}$

While dyslipidemia is one of the elements that contribute in the development of atherosclerosis ${ }^{7}$, besides other factors, hyperhomocysteinemia is considered as an independent predictor of atherosclerosis. ${ }^{14}$ However while probing these facts the researchers were mostly focused on younger age groups (children) and even then the data generated pertaining to these factors were inadequate by several facets; in this back drop this study was conceived and carried out to observe these factors in young as well as in adult epileptic patients who were on carbamazepine monotherapy.

\section{METHODS}

This cross-sectional study was carried out in biochemistry department, Basic Medical Sciences Institute, Jinnah Post Graduate Medical Centre Karachi, from January 2015 to January 2016. Bhesania et al., 2014 ${ }^{15}$ was used as a reference study for sample size calculation by open epi calculator. Two hundred epileptic patients and 100 healthy subjects, aged more than 15 years were recruited in the study. They were divided into three groups. Group A comprised of 100 healthy individuals, Group B comprised of newly diagnosed epileptic patients without antiepileptic therapy and Group C was having epileptic patients on Carbamazepine therapy, which was further divided into C-I (epileptic patients on Carbamazepine therapy less than 1 year $n=33$ ), C-II (epileptic patients on Carbamazepine therapy 1-2 years $n=33$ ) and C-III (epileptic patients on Carbamazepine therapy more than 2 years $n=$ 34). In this study, 163 (54\%) were males and 137 $(46 \%)$ were females. The mean Body Mass Index of the participants was $25 \pm 1.88$. Patients with a history of ischemic heart diseases, liver diseases, hypertension, renal diseases, autoimmune diseases, tobacco smokers or pregnant and lactating women were excluded.

The study was carried out with the approval of the ethical committee of the Jinnah Post Graduate Medical Centre Karachi and Institutional Review Board (IRB) of BMSI, JPMC, Karachi. Informed consent was obtained from all the recruited subjects. The subjects were interviewed in detail regarding their general information, drug history and history regarding their general and surgical ailments. Their physical examination was performed. Venous blood was collected after an overnight fast for the analysis.

Total cholesterol, Triglyceride and HDL-cholesterol were estimated by enzymatic colorimetric method, using kit, manufactured by Merck private limited, France. LDL-cholesterol and VLDLcholesterol were calculated using the Friedewald formula that is, LDL-C = TC - TG/5 -HDL-C and $\mathrm{VLDL}-\mathrm{C}=\mathrm{TG} / 5$. Serum homocysteine level was estimated by Human Homocysteic acid (HCY) ELISA Kit, supplied by Shanghai Yehua Biological Technology Co., Ltd.

Statistical package for Social Sciences (SPSS) version 16 was used for data analysis. Values were entered as mean \pm standard deviation (SD). One-way Analysis of Variance (ANOVA) and post hoc tukey was used for the comparison of means among more than two variables. The Pearson correlation was applied to correlate the levels of 
serum homocysteine with other study variables. A two-tailed $p$-value $<0.05$ was considered significant.

\section{RESULTS}

Significant results were observed in mean total cholesterol, triglyceride, LDL-C, VLDL-C in epileptic patients on carbamazepine therapy for less than 1 year, 1 to 2 years and more than 2 years. Triglyceride/HDL, total Cholesterol/HDL and LDL/HDL ratios were found significant in epileptic patients on carbamazepine therapy for 1 to 2 years and more than 2 years as shown in table 1 ( $p$-value $=0.001)$. No significant difference was found in mean HDL-C among the five groups compared (Table-I).

As per our hypothesis, homocysteine was also found statistically significant in all three groups of patients on carbamazepine therapy (Figure-1).

Bivariate Pearson correlation showed that homocysteine was found significantly and positively correlated with total cholesterol, triglyceride, LDL-C, VLDL-C (Figure-2 to 5) and also with triglyceride/ HDL, LDL/ HDL and cholesterol/ HDL ratios (Table-II) at p-value < 0.01 .

Values were expressed as mean \pm SD.

*Statistically significant as compared to group A, †statistically significant as compared to group B,

- Statistically significant as compared to group C-I, § statistically significant as compared to group C-II $(p<0.05)$.

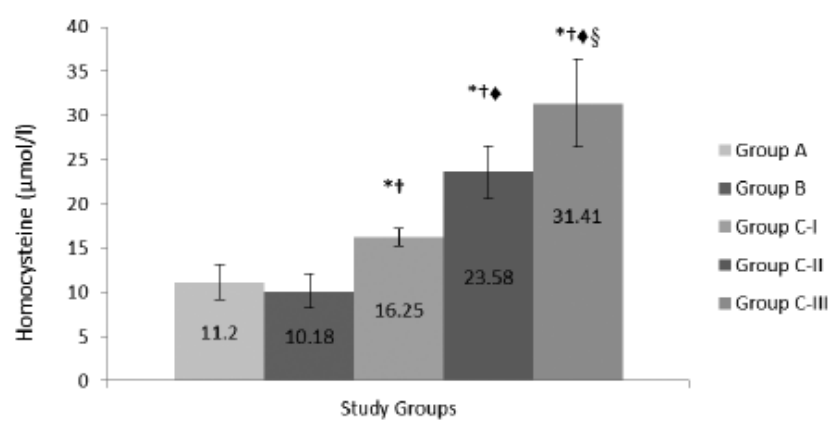

Figure-1. Comparison of Homocysteine ( $\mu \mathrm{mol} / \mathrm{I})$ among study groups

\begin{tabular}{|c|c|c|c|c|c|}
\hline Variable & Group A & Group B & Group C-I & Group C-II & Group C-III \\
\hline Triglyceride (mg/dl) & $\begin{array}{l}125.97 \\
\pm 12.8\end{array}$ & $\begin{array}{l}127.31 \\
\pm 13.17\end{array}$ & $\begin{array}{c}136.02^{*} \dagger \\
\pm 8.66\end{array}$ & $\begin{array}{l}151.2^{*+} \\
\pm 6.31\end{array}$ & $\begin{array}{c}166.37^{\star} \downarrow \S \\
\pm 10.53\end{array}$ \\
\hline LDL-C (mg/dl) & $\begin{array}{l}106.17 \\
\pm 18.3\end{array}$ & $\begin{array}{l}107.18 \\
\pm 16.89\end{array}$ & $\begin{array}{c}122.28^{*} \dagger \\
\pm 8.85\end{array}$ & $\begin{array}{c}136.83^{\star} \\
\pm 9.27\end{array}$ & $\begin{array}{c}150.63^{*} \triangleleft \\
\pm 6.98\end{array}$ \\
\hline VLDL-C (mg/dl) & $\begin{array}{l}25.19 \\
\pm 2.59\end{array}$ & $\begin{array}{l}25.46 \\
\pm 2.63\end{array}$ & $\begin{array}{l}27.20^{*} \dagger \\
\pm 1.73\end{array}$ & $\begin{array}{c}30.24^{\star} \\
\pm 1.26\end{array}$ & $\begin{array}{c}33.27^{\star \star \S} \\
\pm 2.11\end{array}$ \\
\hline LDL/HDL ratio & $\begin{array}{c}2.53 \\
\pm 0.65\end{array}$ & $\begin{array}{c}2.54 \\
\pm 0.59\end{array}$ & $\begin{array}{l}2.82 \\
\pm 0.4\end{array}$ & $\begin{array}{l}3.12^{* \dagger} \\
\pm 0.37\end{array}$ & $\begin{array}{l}3.41^{*} \\
\pm 0.34\end{array}$ \\
\hline TCHDL ratio & $\begin{array}{c}4.12 \\
\pm 0.74\end{array}$ & $\begin{array}{c}4.13 \\
\pm 0.67\end{array}$ & $\begin{array}{c}4.44 \\
\pm 0.44\end{array}$ & $\begin{array}{l}4.80^{*}+ \\
\pm 0.41\end{array}$ & $\begin{array}{c}16^{*+} \\
\pm 0.38\end{array}$ \\
\hline \multicolumn{6}{|c|}{$\begin{array}{l}\text { Table-I. Comparison of Lipid profile among study groups } \\
\text { Values were expressed as mean } \pm \text { SD. } \\
\text { ficant as compared to group A, † Statistically significant as compared to group B, } \\
\text { as compared to group C-I, § Statistically significant as compared to group C-II }(p<0.05) \text {. }\end{array}$} \\
\hline
\end{tabular}




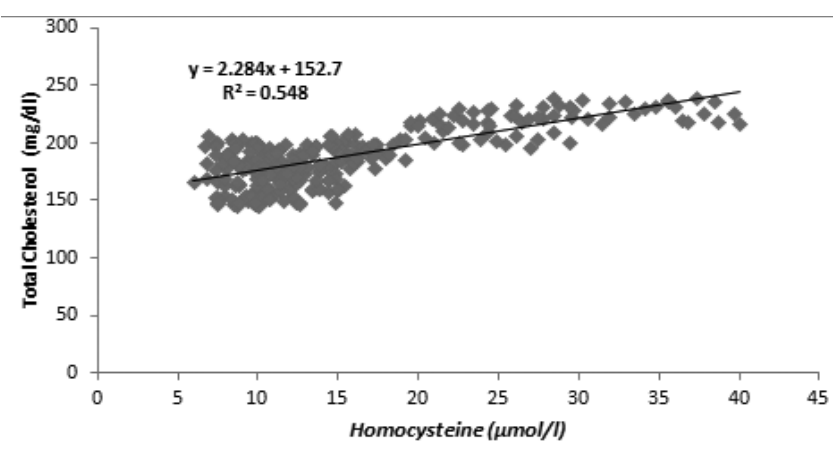

Figure-2. Correlation of Homocysteine ( $\mu \mathrm{mol} / \mathrm{l})$ with Total Cholesterol:

** Statistically significant $<0.01$.

Total Cholesterol was found significantly and positively correlated with homocysteine.

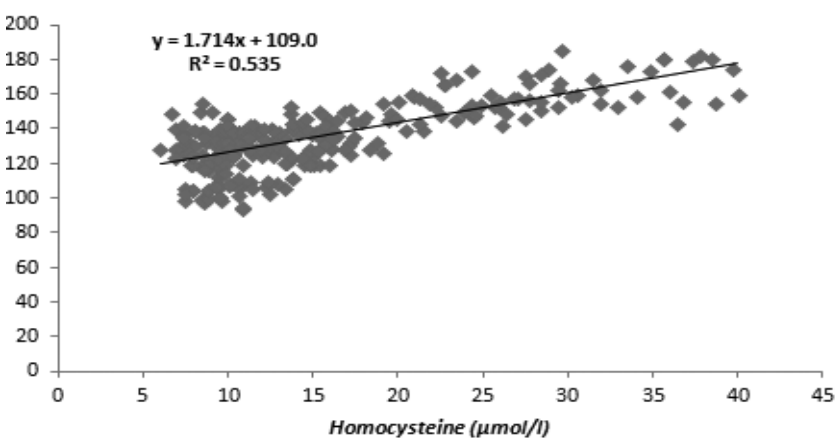

Figure-3. Homocysteine $(\mu \mathrm{mol} / \mathrm{l})$ with TG:

** Statistically significant $<0.01$.

Triglyceride was found significantly and positively correlated with homocysteine.

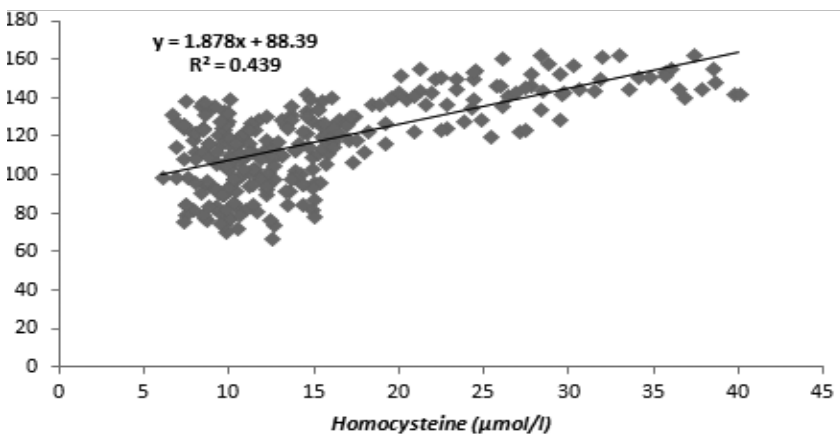

Figure-4. Homocysteine $(\mu \mathrm{mol} / \mathrm{l})$ with LDL-C:

**Statistically significant $<0.01$.

LDL-C was found significantly and positively correlated with homocysteine.

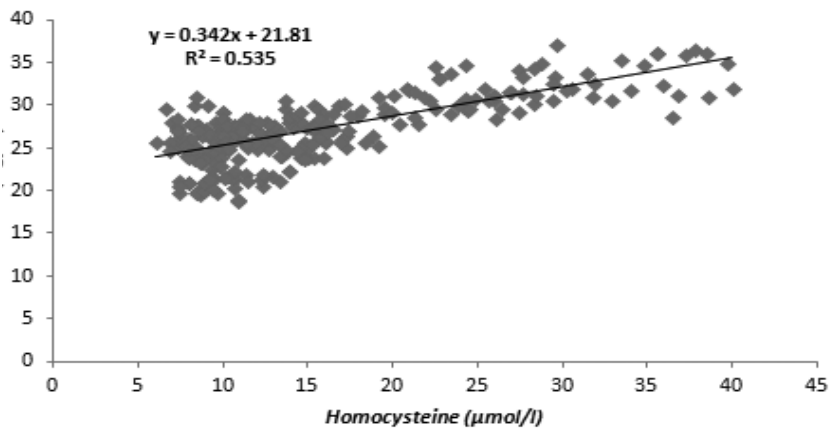

Figure-5. Homocysteine ( $\mu \mathrm{mol} / \mathrm{l})$ with VLDL-C:

**Statistically significant $<0.01$.

VLDL-C was found significantly and positively correlated with homocysteine.

\begin{tabular}{|l|c|}
\hline Variables & Correlation Co-efficient $(\mathbf{r})$ \\
\hline TG/ HDL ratio & $0.477^{* \star}$ \\
\hline LDL/HDL ratio & $0.454^{* \star}$ \\
\hline TC/HDL ratio & $0.469^{* *}$ \\
\hline \multicolumn{2}{|c|}{ Table-II. Correlation of Homocysteine $(\boldsymbol{\mu m o l} / \mathrm{I})$ with } \\
ratios \\
** Statistically significant $<\mathbf{0 . 0 1 .}$
\end{tabular}

\section{DISCUSSION}

Atherosclerosis which eventually leads to ischemic heart disease is the leading cause of death in adults. ${ }^{16}$ Dyslipidemia is one of the major risk factors for the development of atherosclerosis. ${ }^{12}$ The impact of antiepileptic drugs therapy on lipid profile is still controversial in the research arena and more data needs to be generated to formulate enough convincing evidence in this regard. ${ }^{17}$

In this study, we have found out significant increase in blood levels of TC, TG, LDL-C and VLDL-C in different durations of CBZ therapy in comparison with control and newly diagnosed epileptic patients without treatment. However, we were unable to establish statistically significant difference in HDL-C among different groups and HDL-C was not even found to be significantly correlated with serum homocysteine.

These results could be justified on the basis of enzyme induction activity of CBZ. Carbamazepine induces hepatic cytochrome P450 system and there by alter the biotransformation of lipoproteins by a competitive process inferring in 
the increased serum cholesterol level. ${ }^{10}$ However the mechanism by which antiepileptic drugs increase serum TG levels is still to be concretely determined. ${ }^{17}$

The findings of ElMastry et al. ${ }^{10}$ were also in accordance with our study results. Duration of AED therapy with CBZ also seems to be a predictor variable for dyslipidemia as statistically significant elevation in the serum level of TC, TG as well as LDL-C was observed over a period of $1.7 \pm 0.61$ years which further incremented on the next period quartile of $2.9 \pm 0.56$ years; while serum HDL-C level remained insignificant. Plasma cholesterol ester transfer protein and hepatic lipase have main role in the metabolism of HDL-C. It is demonstrated that even in the presence of these proteins HDL-cholesterol ester can be changed to LDL-C. Another important factor is dietary fat which in increased amount causes the increased conversion of HDL-C to LDL-C. ${ }^{10}$

Interestingly there seems to be an obvious consensus on the existence of some sort of dyslipidemia in the epileptic patients on CBZ monotherapy; however the flare of diversity is also very evident among the researchers regarding the duration and type of lipoprotein elevation in this regard. While some of the researchers reported a total band elevation of lipoprotein over a period of approximately one decade ${ }^{18}$ and others considered only TC and LDL-C elevation over a meager period of two years. However they also demonstrated insignificant increase in TG and HDL-C. ${ }^{9}$ Radeef et al even rang the alarm bell on a mere duration of three months of therapy but then again they fail to found any significant elevation in TG. ${ }^{17}$ Adding to the complexity of evidence Keenan et al seems to have a different contrast over the duration of one year; having significant increments in TC and TG levels while trivial changes in LDL-C as well as HDL-C levels. ${ }^{19}$

Even after reporting the mounting favorable evidence in the concurrence to our study results, it would be highly pertinent and desirable to mention relevant disagreements to our study findings and that too on a relatively strong study design with a single follow up after three months of discontinuation of CBZ therapy. Harit et al documented inconsequential variation in the whole lipid profile in patients with prior two years duration of CBZ therapy. Though they themselves admitted their limitation of not having a long term follow up, which was perhaps required to establish the fact beyond reasonable doubt; when it comes to IHD. ${ }^{20}$

Ischemic heart diseases, as an outcome variable was reported more often than not in epileptic patients on CBZ therapy. ${ }^{17}$ Provision of probable justification to this fact could be documented by development of atherosclerosis due to altered lipoprotein ratios (TC/HDL, TG/HDL \& LDL/HDL) in patients on $\mathrm{CBZ}$ therapy. ${ }^{21}$

In our study we have found significant increased TC/HDL, TG/HDL and LDL/HDL ratios in epileptic patients on CBZ therapy over 1-2 years as well as more than 2 years. In concurrence to our study results El-Farahaty et al have reported significant increase in TC/HDL and LDL/HDL ratios over 2 years of therapy. ${ }^{22}$ More so Keenan et al have also reported significant increase in TC/HDL ratio over median duration of therapy of 2.8 years. ${ }^{19}$ However Harit et al. ${ }^{20}$ have not found statistically significant difference in TC/HDL and LDL/HDL ratios.

Homocysteine is thought to be an important vascular injury marker and its elevation is documented to be associated with prolong use of enzymeinducing AEDs. ${ }^{23,24}$ Hyperhomcysteinemia seems to be associated with high mortality rate due to ischemic heart diseases. It has been demonstrated by the researchers that an increment in $5 \mathrm{mmol} / \mathrm{l}$ in plasma homocysteine level can infer in enhanced risk of cardiovascular disease by $20 \%{ }^{6}$

Our study also concluded that rise in the level of homocysteine is correlated with the duration of CBZ therapy; which is in concurrence with the published research data., 92,25,26 However some researchers tend to differ, transcribing inconsequential changes in the Hcy levels on a comparatively shorter duration of therapy. ${ }^{27,28}$ 
It would be really pertinent to mention that we were unable to document statistically significant changes in Hcy levels between controls and newly diagnosed epileptic patients without treatment. Researchers justify this finding by transcribing that may be use of AEDs is the principal cause of Hcy elevation. Furthermore it has also been documented that HHcy is a result of decrease absorption and increase metabolism of vitamin B12 and folate because of the use of AED. ${ }^{29}$

Our study has due limitations as well, firstly due to the cross sectional study design, secondly administrative as well as financial management of large sample size and last but not the least time limitations. Most importantly the study was conducted in a tertiary care hospital so; it may not reflect the actual disease status of the general population.

In the light of our study findings we would like to recommend that epileptic patients on carbamazepine therapy should be routinely monitored for homocysteine level to check the progression of atherosclerotic changes and homocysteine should be considered as a potential risk factor for atherosclerotic changes in epileptic patients on CBZ therapy.

\section{CONCLUSION}

The results indicated that dyslipidemia was associated with hyperhomocysteinemia and homocysteine have an important role in the development of atherosclerotic changes in epileptic patients on carbamazepine therapy. It may be considered as an early predictor to assess the risk of atherosclerosis in these patients.

\section{Copyright@ 15 June, 2019.}

\section{REFERENCES}

1. Banerjee TK, Dutta S, Ray BK, Ghosal M, Hazra A, Chaudhuri A, Das SK. Epidemiology of epilepsy and its burden in Kolkata, India. Acta Neurol Scand 2015; 132: 203-211. doi: 10.1111/ane.12384.

2. Ahmed SA, Faraz A, Ramzan MA, Fateema S, Nabeeha E, Rizvi SS, Chohan MT, Nafees T, Khan Gl. Awareness and knowledge on epilepsy among undergraduate medical students in Pakistan. Intern Arch Med 2015; 8:7. doi: 10.3823/1721.
3. Smithson MH, Colwell B, Hanna J. Sudden unexpected death in epilepsy: Addressing the challenges. Curr Neurol Neurosci Rep 2014; 14:1-6. doi 10.1007/s11910014-0502-4.

4. Tayal D, Goswami B, Koner BC and Mallika V. Role of homocysteine and lipoprotein $(A)$ in atherosclerosis: An update. Biomed. Res. 2011; 22 (4): 391-405.

5. Perna AF, Ingrosso D, Lombardi C, Acanfora F, Satta $\mathrm{E}$, Cesare CM, et al. Possible mechanisms of homocysteine toxicity. Kidney International 2003; 63:137-140.

6. Kapoor A, Zuberi NA, Rathore MI, Baig M. Serum homocysteine level in vegetarians in district Tharparker, Sindh. Pak J Med Sci 2015; 31:127-130. doi.org/10.12669/pjms.311.6111.

7. Reiner Z, Catapano AL, Backer GD, Graham I, Taskinen MR, Wiklund $O$ et al. ESC/EAS Guidelines for the management of dyslipidaemias. The Task Force for the management of dyslipidaemias of the European Society of Cardiology (ESC) and the European Atheroscierosis Society (EAS). Eur Heart J 2011; 32:1769-1818.

8. Lewington S, Whitlock G, Clark R, Sherliker P, Emberson J, Halsey J, Qizilbash N, Peto R, Collins R. Blood cholesterol and vascular mortality by age, sex, and blood pressure: A meta-analysis of individual data from 61 prospective studies with 55,000 vascular deaths. Lancet 2007; 370:1829-1839.

9. Chuang YC, Chuang HY, Lin TK, Chang CC, Lu CH, Chang WN, Chen SD, Tan TY, Huang CR, Chan SHH. Effects of long term antiepileptic drug monotherapy on vascular risk factors and atherosclerosis. Epilepsia 2012; 53:120-128.

10. ElMasry HMA, Hamed AMM, Elazeem H MH, Hassan $\mathrm{AH}$, Abolfotouh MM. Sub clinical hypothyroidism and dyslipidemia in upper egyptian epileptic children on carbamazepine therapy. Am J Res Commun 2013; 1:167-181.

11. Kunitomo M. Oxidative stress and atherosclerosis. Yakurigaku Zasshi. 2007; 127:1997-2014.

12. Tan TY, Lu CH, Chuang HY, Lin TK, Liou CW and Chang WN. Long-term antiepileptic drug therapy contributes to the acceleration of atherosclerosis. Epilepsia 2009; 50:1579-1586. doi: 10.1111/j.1528-1167.2009.02024.x.

13. Anderson GD. Pharmacogenetics and enzyme induction/inhibition properties of antiepileptic drugs. Neurology 2004; 63: 3-8. 
14. Emeksiz HC, Serdaroglu A, Biberoglu G, Gulbahar O, Arhan E, Cansu A, Arga M, Hasanoglu A. Assessment of atherosclerosis risk due to the homocysteineasymmetric dimethylarginine-nitric oxide cascade in children taking antiepileptic drugs. Seizure 2013; 22:124-127. doi: 10.1016/j.seizure.2012.11.007.

15. Bhesania NH, Rehman A, Savul IS, Zehra N. Knowledge, attitude and practices of school teachers towards epileptic children in Karachi, Pakistan. Pak J Med Sci 2014; 30:220-224. doi: http://dx.doi.org/10.12669/ pjms.301.4307.

16. Yilmaz E, Dos $Y$, Gurgoze MK and Gungor S. Serum lipid changes during anticonvulsive treatment. Serum lipids in epileptic children. Acta neurol. belg. 2001; 101: 217-220.

17. Radeef MY, Al-Shamma K, Hammash BM. The effect of treatment with antiepileptic drugs (Carbamazepine, valproic acid, topiramate, and their Combination) On Lipid Profile, C-Reactive Protein, And Renal Function in Iraqi Epileptic Patients. Tikrit $\mathrm{J}$ Pharmaceut Sci 2013; 9:1-18.

18. Mahmood IH and Mded ZK. Effects of carbamazepine on blood pressure, serum glucose concentration, lipid profile and prevalence of metabolic syndrome in epileptic patients. Tikrit J Pharmaceut Sci 2012; 8:102-109.

19. Keenan N, Sadlier LG, Wiltshire E. Vascular function and risk factors in children with epilepsy: Associations with sodium valproate and Carbamazepine. Epilepsy Research 2014; 108:1087-1094. doi. org/10.1016/j. epilepsyres.2014.04.006.

20. Harit D, aggarwal A, Karla S, Chhillar N. Effect of carbamazepine and valproate monotherapy on cardiovascular risks in epileptic children. Pediatric Neurol 2015; 53:88-90. doi.org/10.1016/j. pediatrneurol.2015.02.018.

21. Zuberi NA and Perveen T. Derangement of lipid profile in antiepileptic drugs treated patients in local population. Pak J Biochem Mol Biol. 2012; 45:138-141.
22. El-Farahaty RM, El-Mitwalli A, Azzam H, Wasel Y, Elrakhawy MM and Hasaneen BM. Atherosclerotic effects of long-term old and new antiepileptic drugs monotherapy: A cross-sectional comparative study. J. Child Neurol 2015; 30:451-457. doi: $10.1177 / 0883073814551388$.

23. Mintzer S, Skidmore CT, Abidin CJ, MoralesMC, Chervoneva I, Capuzzi DM, Sperling MR. Effects of antiepileptic drugs on lipids, homocysteine, and C-Reactive protein. Ann Neurol 2009; 65:448-456.

24. Belcastro V, Striano P, Gorgone G, Costa C, Ciampa C and Caccamo D. Hyperhomocysteinemia in epileptic patients on new antiepileptic drugs. Epilepsia 2010; 51:274-279. doi/10.1111/j.1528-1167.2009.02303.x/full.

25. Verrotti A, Pascarella R, Trotta D, Giuva T, Morgese G and Chiarelli F. Hyperhomocysteinemia in children treated with sodium valproate and Carbamazepine. Epilepsy Res 2000; 41:253-257.

26. Karabiber H, Sonmezgoz E, Ozerol E, Yakinci C, Otlu B and Yologlu S. Effect of valproate and Carbamazepine on serum levels of homocysteine, vitamin B12 and folic acid. Brain Dev 2003; 25:113-115.

27. Kumar V, Aggarwal A, Sharma S, Chillar N, Mittal H and Faridi MMA. Effect of carbamazepine therapy on homocysteine, Vitamin B12 and folic acid levels in children with epilepsy. Indian Pediatr. 2013; 50:469-72.

28. Abd El Dayem SM, Saleh ON, Emara NA, Kandil ME, Shatla RH and Elgammal S. Evalution of homocysteine, folic acid and Vitamin B12 levels among Egyptian children with idiopathic epilepsy. Maced J Med Sci. 2014; 7:109-113. doi.org/10.3889/MJMS.18575773.2014.0358.

29. Eldeen ON, Eldayem SMA, Shatla RH, Omara NA, Elgammal SS. Homocysteine, folic acid and vitamin B12 levels in serum of epileptic children. Egypt. J. Med. Hum. Genet. 2012; 13:275-280.

\begin{tabular}{|c|c|c|c|}
\hline \multicolumn{4}{|c|}{ AUTHORSHIP AND CONTRIBUTION DECLARATION } \\
\hline Sr. \# & Author(s) Full Name & Contribution to the paper & Author(s) Signature \\
\hline 1 & Shazia Bano & $\begin{array}{l}\text { Designed the study, collected } \\
\text { the samples, interpreted } \\
\text { the data and prepared the } \\
\text { manuscript. }\end{array}$ & \\
\hline 2 & Syed Munawar Alam & $\begin{array}{l}\text { Helped in designing and } \\
\text { finalizing the manuscript. }\end{array}$ & \\
\hline 3 & Saima Iram & $\begin{array}{l}\text { Helped in sample collection } \\
\text { and analyzing the manuscript. }\end{array}$ & \\
\hline
\end{tabular}

